University of Nebraska - Lincoln

DigitalCommons@University of Nebraska - Lincoln

9-2009

\title{
Retrieval of Foliar Information about Plant Pigment Systems from High Resolution Spectroscopy
}

\author{
Susan L. Ustin \\ University of California, Davis, Davis, CA \\ Anatoly A. Gitelson \\ University of Nebraska at Lincoln, agitelson2@unl.edu \\ Stéphane Jacquemoud \\ Institut de Physique du Globe de Paris, Université Paris Diderot \& Institut de Physique du Globe de Paris, \\ Géophysique spatiale et planétaire - Bâtiment Lamarck Case 7011, 35 rue Hélène Brion 75013 Paris, \\ France \\ Michael Schaepman \\ Center for Geo-Information, Wageningen University, 6700AA Wageningen, The Netherlands \\ Gregory P. Asner \\ Department of Global Ecology, Carnegie Institution of Science, 260 Panama Street, Stanford, CA 94305, \\ USA
}

See next page for additional authors

Follow this and additional works at: https://digitalcommons.unl.edu/natrespapers

Part of the Natural Resources and Conservation Commons

Ustin, Susan L.; Gitelson, Anatoly A.; Jacquemoud, Stéphane; Schaepman, Michael; Asner, Gregory P.; Gamon, John A.; and Zarco-Tejada, Pablo, "Retrieval of Foliar Information about Plant Pigment Systems from High Resolution Spectroscopy" (2009). Papers in Natural Resources. 165.

https://digitalcommons.unl.edu/natrespapers/165

This Article is brought to you for free and open access by the Natural Resources, School of at DigitalCommons@University of Nebraska - Lincoln. It has been accepted for inclusion in Papers in Natural Resources by an authorized administrator of DigitalCommons@University of Nebraska - Lincoln. 


\section{Authors}

Susan L. Ustin, Anatoly A. Gitelson, Stéphane Jacquemoud, Michael Schaepman, Gregory P. Asner, John A. Gamon, and Pablo Zarco-Tejada 


\title{
Retrieval of foliar information about plant pigment systems from high resolution spectroscopy
}

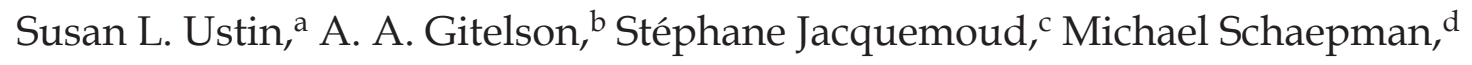 \\ Gregory P. Asner, ${ }^{\mathrm{e}}$ John A. Gamon, ${ }^{\mathrm{f}}$ and Pablo Zarco-Tejada $\mathrm{g}$
}

a Center for Spatial Technologies and Remote Sensing, Department of Land, Air, and Water Resources, University of California, Davis, Davis, CA 95616, USA; email slustin@ucdavis.edu (Corresponding author)

b CALMIT, School of Natural Resources, University of Nebraska-Lincoln, 303 Hardin Hall, 3310 Holdrege Lincoln, NE 68583-0973, USA; email agitelso@unlnotes.unl.edu

${ }^{\mathrm{c}}$ Institut de Physique du Globe de Paris, Université Paris Diderot \& Institut de Physique du Globe de Paris, Géophysique spatiale et planétaire - Bâtiment Lamarck Case 7011, 35 rue Hélène Brion 75013 Paris, France; email jacquemoud@ipgp.fr

d Center for Geo-Information, Wageningen University, 6700AA Wageningen, The Netherlands; email michael.schaepman@geo.uzh.ch

${ }^{\text {e }}$ Department of Global Ecology, Carnegie Institution of Science, 260 Panama Street, Stanford, CA 94305, USA; email gpa@stanford.edu

${ }^{\mathrm{f}}$ California State University Los Angeles, CA, USA; email jgamon@gmail.com

gInstituto de Agricultura Sostenible (IAS), Consejo Superior de Investigaciones Científicas (CSIC), Spain; email pzarco@ias.csic.es

\begin{abstract}
Life on Earth depends on photosynthesis. Photosynthetic systems evolved early in Earth history and have been stable for 2.5 billion years, providing prima facie evidence for the significance of pigments in plant functions. Photosynthetic pigments fill multiple roles from increasing the range of energy captured for photosynthesis to protective functions. Given the importance of pigments to leaf functioning, greater effort is needed to determine whether individual pigments can be identified and quantified in vivo using high fidelity spectroscopy. We review recent advances in detecting plant pigments at the leaf level and discuss successes and reasons why challenges remain for robust remote observation and quantification. New methods to identify and quantify individual pigments in the presence of overlapping absorption features would provide a major advance in understanding their biological functions, quantifying net carbon exchange, and identifying plant stresses.
\end{abstract}

Keywords: plant pigments, chlorophyll a, chlorophyll b, carotenes, xanthophyll pigments, anthocyanin pigments, absorption features, spectral measures of pigments, spectroscopy

\section{Introduction}

Life on Earth is driven by photosynthesis, producing both oxygen and organic matter (Nelson \& Yocum, 2006). Photosynthesis is one of the earliest biological processes to evolve and the pigment systems in modern photosynthetic bacteria, algae, and higher plants appeared at least 2.5 billion years ago (Olson and Blankenship, 2004; Kiang et al., 2007). Photosynthetic pigments including chlorophylls a, b, and several carotenoid pigments date from this period. The length and stability of this record, and the various roles of pigments in photosynthesis, protection and defense, demonstrate the functional importance of their composition, associated protein complexes, and chloroplast structure. Their significance for life on Earth provides the rationale for improving our capability to remotely measure them. Furthermore, the stability of chlorophyll molecules makes them a target, along with water, in the search for extraterrestrial life (Arnold et al., 2002; Wolstencroft and Raven, 2002; Seager et al., 2005). The range of characteristic reflectance patterns varies among different taxonomic groups of photosynthetic organisms in the visi- ble and near-infrared spectrum as illustrated in Figure 1 (Kiang et al., 2007). Although terrestrial and aquatic plants and mosses share a common photosynthetic apparatus, in contrast to some algae, lichens, and bacteria, reflectance differences among different taxa exist across the range of wavelengths that relate to both structure and biochemistry.

Developing methods to quantify pigment content and composition from remotely sensed data would clearly provide a capability that could advance understanding of photosynthetic processes (e.g., light regulation, photooxidation, chlorophyll fluorescence) and provide insight into detection and monitoring of foliar condition (e.g., environmental stressors). This review provides a brief summary of the major plant pigments and their ecophysiological functions and the most widely used spectroscopic methods for retrieving information from high spectral resolution remote sensing. This paper is dedicated to Professor Alexander F.H. Goetz, who led a major investigation into the potential for measuring plant biochemistry from narrow-band imaging spectrometry in the early 1990s. This activity stimulated international research in the detection of plant biochemicals and many advances in mea- 


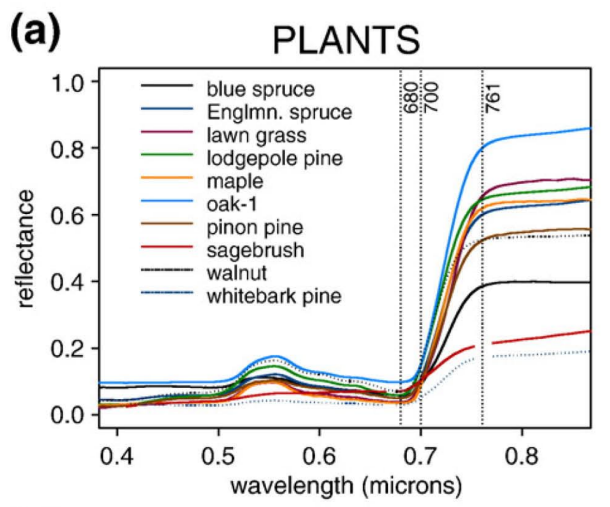

(c)

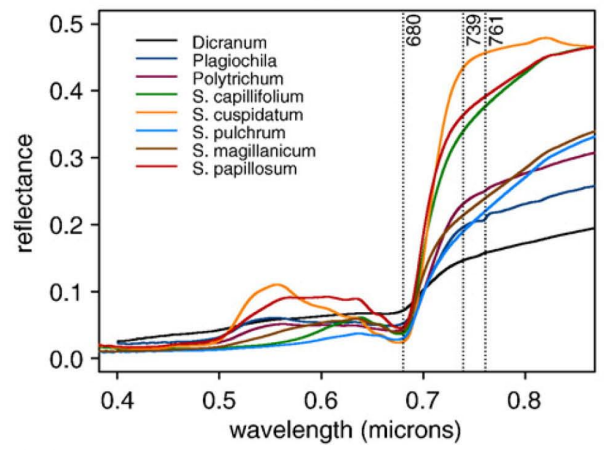

(e)

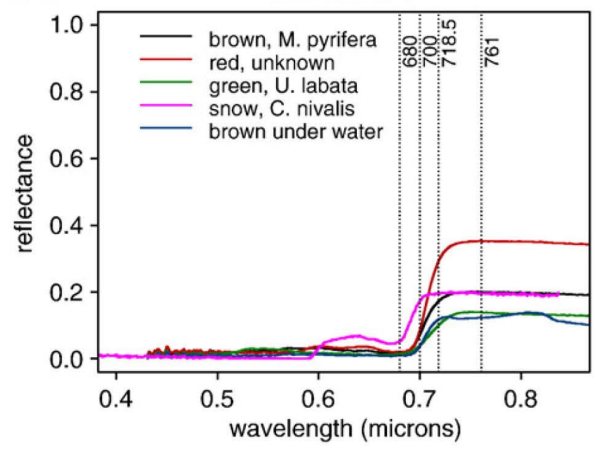

(b) AQUATIC PLANTS

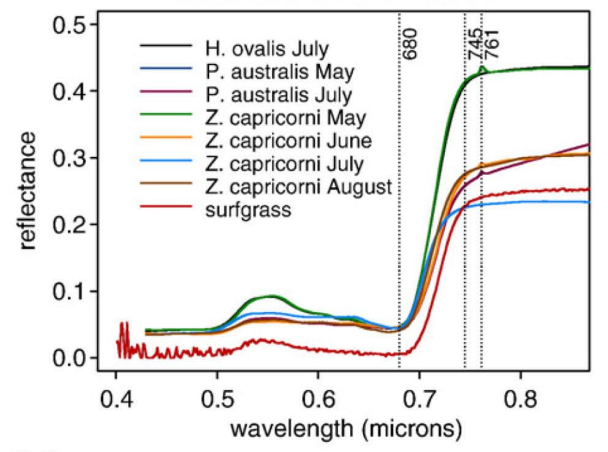

(d)

LICHENS

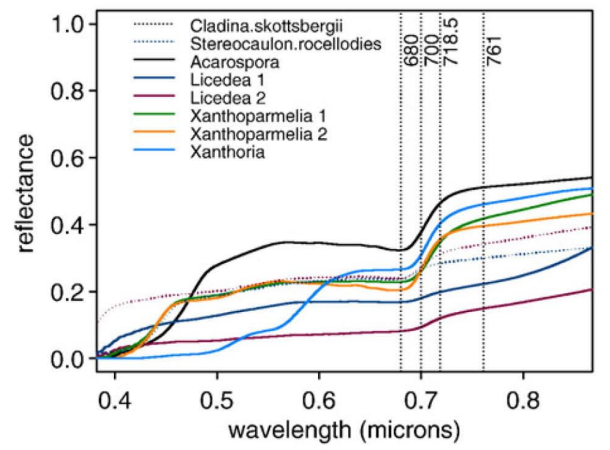

(f)

BACTERIA

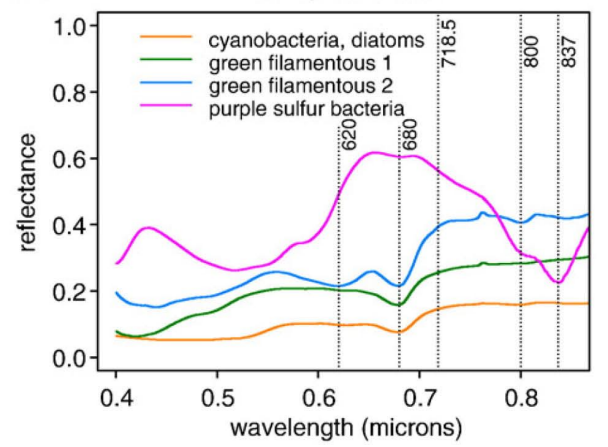

Figure 1. Characteristic reflectance patterns among major groups of photosynthetic organisms in the visible and near-infrared spectrum. The oxygen absorption band, included for reference, is the vertical bar at $761 \mathrm{~nm}$ on the near-infrared plateau, shorter wavelength bars indicate the primary chlorophyll band at $680 \mathrm{~nm}$ and the region of the red-edge inflection point (reproduced from Kiang et al., 2007).

suring leaf pigments from reflectance data originate from this effort. To narrow the scope of this review, we focus primarily on reflectance measurements, at the leaf level, emphasizing advances in the past 15-20 years, and examining two types of quantitative approaches: (1) empirical methods and (2) physically based radiative transfer models and quantitative methods.

\section{Photosynthesis and other functions of leaf pigments}

Absorption of light in the visible spectrum by plant pigments produces a unique spectral reflectance signature. Light is captured by the process of photosynthesis (Govindjee \& Krogmann, 2004) and the light energy is stored as carbohydrate, through a series of electron transfers that occur on the thylakoid membranes in chloroplasts. In the intact chloroplast, pigment-protein complexes are organized into two photosystems that harvest light and transfer energy to the reaction centers. Besides chlorophyll $\mathrm{a}$ and $\mathrm{b}$, the photosynthetic antenna (the organized association of pigments that capture photons and transfer energy to the reaction centers) contain other membrane-bound accessory pigments that include $\beta$-carotene, lutein and xanthophyll cycle pigments (Lichtenthaler, 1987). Figure 2 shows the absorption spectra of chlorophyll $\mathrm{a}$ and $\mathrm{b}$ and $\beta$-carotene. Accessory pigments increase the spectrum over which light can be absorbed and also perform other functions, not all of which are fully understood, but which alter the efficiency of photon capture and/ or provide protective and defensive functions, e.g., avoiding damage to the reaction centers under excess UV light or freezing temperatures. For example, under high illumination conditions, light intensity may exceed the capacity for electron transfer between the photosystems and some carotenoid pigments, such as xanthophylls, are involved with protection from photooxidation and photoinhibition (Demmig-Adams \& Adams, 1996) and with release of excess solar energy through leaf fluorescence.

\section{Measuring the absorption spectra of foliar pigments from high resolution spectroscopy}

One factor that has limited our ability to quantify individual pigments from reflectance data is that we do not precisely know 
their absorption characteristics. It has long been noted (Rühle \& Wild, 1979) that extracted chlorophyll absorption peaks are shifted about $20 \mathrm{~nm}$ to shorter wavelengths than observed in reflectance from intact leaves. The wavelength positions of maximum absorption vary with the extraction solvent used, due to differences in polarity, and the loss of pigment-protein interactions (Porra, 2002). The absorption maxima of chlorophyll a when extracted in diethyl ether are at 430 and $662 \mathrm{~nm}$, and chlorophyll b has peaks located at 453 and $642 \mathrm{~nm}$ (Figure 2). $\beta$-carotene extracted in hexane absorbs at 451 and $470 \mathrm{~nm}$ (Du et al., 1998). In the presence of multiple accessory pigments and nonphotosynthetic cytoplasmic pigments like anthocyanin, it becomes clear why identification and quantification of individual pigments in the intact leaf has been difficult to obtain from their spectral absorptance signatures at specific bands (Buschmann et al., 1994). Multiple scattering from within the leaf further complicates pigment retrievals making remote detection even more challenging, as further discussed below.

A large number of narrow-band spectral methods have been proposed to detect plant pigments, ranging from simple band ratios to radiative transfer methods. Indexes currently used for estimating chlorophyll from leaf optical properties exploit the differences in reflectance between healthy and stressed vegetation in the visible and the red edge (Horler et al., 1983; Vogelmann et al., 1993; Carter, 1994; Carter and Spiering, 2002; ZarcoTejada et al., 2001; Sims and Gamon, 2002; Malenovský et al., 2006). These indexes are classified into red/NIR ratios, green and red edge indexes, and derivative indexes. Table 1 provides examples of these indexes; see more comprehensive reviews of chlorophyll indexes in Blackburn $(1998,2007)$, le Maire et al. (2004), and Zarco-Tejada et al. (2005a, 2005b).

Grossman et al. (1996) tested various regression methods on several leaf datasets and concluded that maximum correlations were produced at different wavelengths, which depended on the index and whether the pigment was expressed on an area or mass basis. Blackburn (1998) reviewed the ability of several ratio-based indexes, RARS ${ }_{a^{\prime} b}$ PSSR $_{a^{\prime} b}$ and PSND $a_{a^{\prime} b}$ (Table 1) and first and second derivatives of the reflectance and the $\log 1 / \mathrm{R}$ (Yoder \& Pettigrew-Crosby, 1995) to predict contents of chlorophyll a, b and carotenoids, and found best performance from PSSR and PSND indexes. (Blackburn, 1998) and (Blackburn, 2007) found strong but non-linear relationships, typically either power or exponential fits, could be developed at either leaf or canopy scales. He concluded that maximum correlations varied with wavelengths, index, and whether the analysis was on an area or mass basis.

Despite problems in identifying specific wavebands for individual pigments, the earliest attempts to use spectroscopy focused on estimating the content of total photosynthetic pigments using ratios of different spectral bands (e.g., simple ratio as $\mathrm{R}_{\mathrm{NIR}}$ / $R_{\text {red }}$ ) or the normalized difference vegetation indexes (Table 1 ). As interest in narrow-band spectrometry increased, other ratio-based indexes or simple transforms of band combinations were developed as practical methods of analysis. Similarly, the use of first and second derivatives, which were applied across the full spectrum, came into common use in the 1990s. Derivative analyses, discussed in the following section, are primarily focused on the red edge, which is the long wavelength edge of the chlorophyll absorption, in the wavelengths between 700 and $750 \mathrm{~nm}$.

From the beginning of systematic earth observation, remote sensing has focused on measuring plant "greenness", often described as synonymous with chlorophyll content. There is a close relationship between photosynthetic capacity, estimated by pigment contents, and net primary production that is captured to first approximation by the greenness indicators measured by broad-band multispectral instruments (Gates et al., 1965; Monteith, 1976; Sellers, 1985, 1987; Asrar et al., 1984). Many band com- binations in the visible spectrum have been used to estimate total pigments as illustrated by the examples shown in Table 1 . This list is not exhaustive but it does cover the commonly used methods for leaf analysis, while also including more recent examples.

The empirical nature of the early studies, although based on a physiological understanding of absorption spectra of photosynthetic pigments, produced variable results when applied to new conditions due to the range of analytical methods used, experimental conditions, and characteristics of the species. At the leaf scale, when applied to a limited number of species or phenologic conditions, such as in agricultural fields or grasslands, indexes have provided good results despite lack of agreement on optimal methods, as attested to by the extensive literature. Despite the search for a universal method, no one method has been adopted as satisfactory under all growth and environmental conditions.

\section{Measuring photosynthetic capacity in chlorotic and healthy leaves}

Within a species, a variety of factors, including growth stage, irradiance, and various environmental stress conditions, can change the total pigment content and the chlorophyll a:b ratio (Anderson et al., 1988). Changes in the wavelength of the red edge inflection point position (IPP) have been observed for different species (Kiang et al., 2007), time during the growing season (Gates et al., 1965; Horler et al., 1983; Belanger, 1990) and from environmental stresses (Chang and Collins, 1983; Milton et al., 1983; Ustin and Curtiss, 1990; Hoque and Hutzler, 1992). Chlorosis increases reflectance across the visible spectrum and

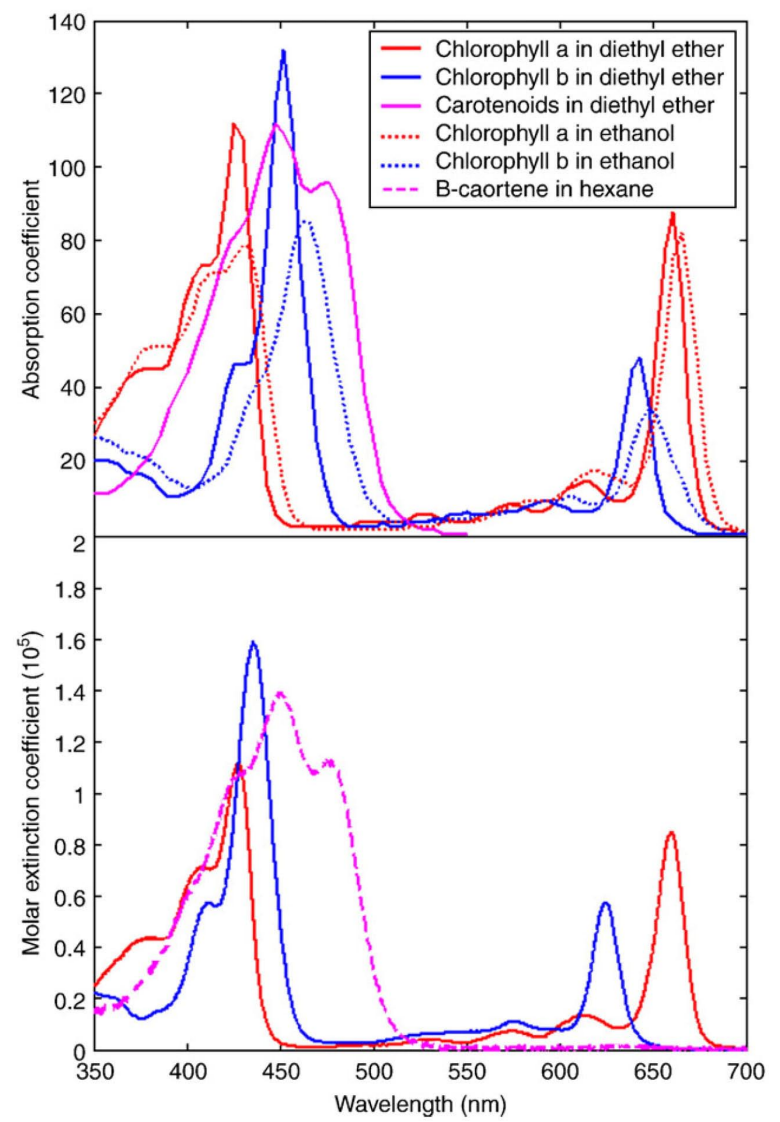

Figure 2. (upper) Differences in absorption spectra of chlorophyll a, chlorophyll $\mathrm{b}$ and $\beta$-carotene in diethyl ether and chlorophyll $\mathrm{a}$ and $\mathrm{b}$ in ethanol. (lower) Molar extinction coefficient of chlorophyll $a$ and $b$ dissolved in diethyl ether and $\beta$-carotene dissolved in hexane (reproduced from Lichtenthaler, 1987; Du et al., 1998). 
causes a shift to shorter wavelengths (blue-shift) of the red-edge IPP, due to narrowing of the chlorophyll absorption feature and a reduction in depth (Ustin \& Curtiss, 1990). Gates et al. (1965) and Collins (1978) provided early observations of a blue shift of the red edge which was attributed to the loss of chlorophyll. Rock et al. (1988) noted a disproportional loss of chlorophyll b accompanied by a blue shift of the IPP for foliage exposed to air pollution. In contrast, under increased chlorophyll content, the chlorophyll absorption feature deepens and broadens (e.g., Buschmann \& Nagel, 1993) causing a red-shift of IPP (Collins, 1978). Kiang et al. (2007) note that the red-edge shifts of IPP from shorter to longer wavelengths for species ranging from algae, lichens, mosses, to aquatic and terrestrial plants. Thus, this index is best applied to variation within a vegetation type to detect stress and between types when it is used to identify taxa. Several index methods have been used to detect red-edge shifts in narrow band spectra (Table 1).

\section{Using the red edge to detect stress}

Most early studies of the red edge used a first or second derivative or the amplitude of the derivative to identify the wavelength at the inflection point, which was then correlated with chlorophyll content (Horler et al., 1983; Wessman, 1990). Figure 3 illustrates how environmental stressors, in this case oil contamination, in a grassland site with relatively little variation in leaf area index can affect the wavelength position of the inflection point (Figure 3a) and how the IPP can be used to map spatial variation in chlorophyll content due to the oil contamination (Figure $3 b$ ).

Despite 30 years of research defining the relationships between pigment content and the red edge using various spectral indexes, the red edge remains an area of active research (e.g., Gitelson et al., 1996; le Maire et al., 2004; Asner et al., 2005; Zarco-Tejada et al., 2005a; Sims et al., 2006). Although the use of derivatives to estimate the red edge position is widely used, because of their sensitivity to noise, other methods e.g., the inverted Gaussian of Miller et al. (1990) are now preferred. Recently, Cho and Skidmore (2006) proposed an improved method to estimate the red-edge inflection wavelength using intersecting lines originating from the shoulders of the derivative. More research is needed to understand precisely what controls the position of long wavelength side of the chlorophyll absorption band. For example, Curtiss and Ustin (1989) observed a broadening of the chlorophyll absorption band in ponderosa pine needles following exposure to atmospheric ozone, which they interpreted as a red-shift that mimicked increased chlorophyll content rather than a blue-shift which is expected under lower chlorophyll content. This effect was hypothesized to be due to increasing disorder in the chloroplast with ozone exposure, a pattern consistent with observations that an early sign of ozone injury is granulation of the thylakoid membranes. Recently Noomen et al. (2006) reported that exposure to natural ethane gas caused a small red shift in corn reflectance and a significant decrease in absorption in the $550-750 \mathrm{~nm}$ region.

\section{Leaf fluorescence and stress detection}

Use of remotely sensed fluorescence to estimate photosynthetic activity began in the oceanography community to detect phytoplankton productivity (e.g., Kim, 1973). For both marine and terrestrial applications, two types of systems have been used, active and passive lasers. Marine systems usually use lasers in the blue spectral region to excite photosystem II activity, with chlorophyll fluorescence being observed in the $730 \mathrm{~nm}$ region. Passive systems rely on measuring natural fluorescence stimulated by sunlight. Although the signal is small, as spectral resolution in the visible spectrum and signal/noise in spectrometers have increased, interest in using this technology to directly observe photosynthetic functioning has become of more interest to plant physiologists and ecologists (Lichtenthaler, 1988). Figure 4 shows the wavelength specific absorption of light excitation by a UV laser and corresponding chlorophyll fluorescence emission for a typical leaf.

Several authors have noted a double peak in the first derivative of leaf reflectance around 700-725 nm (Horler et al., 1983;

Table 1. Spectral indexes developed as chlorophyll indicators.

\begin{tabular}{|c|c|c|c|}
\hline Index & Short & Formula & Source \\
\hline \multicolumn{4}{|l|}{ Single wavelengths } \\
\hline Reciprocal Reflectance & RR & $R_{700}^{-1}$ & Gitelson et al. (1999) \\
\hline $\begin{array}{l}\text { Logarithm of Reciprocal } \\
\text { Reflectance }\end{array}$ & LRR & $\log R_{737}^{-1}$ & Yoder and Pettigrew-Crosby (1995) \\
\hline \multicolumn{4}{|l|}{ Combinations of wavelengths } \\
\hline Waveband Ratios & Ratios & $\begin{array}{l}R_{N I R} / R_{B^{\prime}} R_{N I R} / R_{G^{\prime}} R_{N I R} / R_{R^{\prime}} \\
R_{N I R} / R_{R E^{\prime}} R_{B} / R_{G^{\prime}} R_{B} / R_{R^{\prime}} R_{R} / R_{G}\end{array}$ & $\begin{array}{l}\text { Aoki et al. (1980, 1986), Vogelmann et al. (1993), Carter (1994), } \\
\text { Gitelson and Merzlyak, 1994, 1996, 1997), Datt (1998), } \\
\text { Maccioni et al. (2001), Sims and Gamon (2002) }\end{array}$ \\
\hline Modified Red-edge Ratio & $\mathrm{mSR}$ & $m S R=\left(R_{750}-R_{445}\right) /\left(R_{705}-R_{445}\right)$ & Sims and Gamon (2002) \\
\hline Pigment Specific Simple Ratio & PSSR & $\begin{array}{l}\operatorname{PSSR}_{a}=R_{800} / R_{675} \\
\operatorname{PSSR}_{b}=R_{800} / R_{650}\end{array}$ & Blackburn $(1998,1999)$, Sims and Gamon (2002) \\
\hline $\begin{array}{l}\text { Ratio Analysis of Reflectance } \\
\text { Spectra }\end{array}$ & RARS & $\begin{array}{l}R_{A R S_{a}}=R_{675} / R_{700} \\
\operatorname{RARS}_{b}=R_{675} /\left(R_{650} \times R_{700}\right)\end{array}$ & Chappelle et al. (1992), Blackburn (1999) \\
\hline $\begin{array}{l}\text { Normalized Difference } \\
\text { Vegetation Index }\end{array}$ & NDVI & $N D V i=\left(R_{N I R}-R_{R}\right) /\left(R_{N I R}+R_{R}\right)$ & Deering (1978), Datt (1998) \\
\hline Red-edge NDVI & mNDVI & $\begin{array}{l}m N D V I=\left(R_{750}-R_{705}\right) /\left(R_{750}+R_{705}\right) \\
\text { Datt (1999), Sims and Gamon (2002)) }\end{array}$ & Gitelson and Merzlyak (1994), Gamon and Surfus (1999), \\
\hline $\begin{array}{c}\text { Modified Red-edge Normalized } \\
\text { Difference Vegetation Index }\end{array}$ & mNDI & $m N D V I=\left(R_{750}-R_{705}\right) /\left(R_{750}+R_{705}-2 R_{445}\right)$ & Sims and Gamon (2002) \\
\hline Green NDVI & gNDVI & $g N D V I=\left(R_{750}-R_{G}\right) /\left(R_{750}+R_{\mathrm{G}}\right)$ & Gitelson et al. (1996), Datt $(1998,1999)$ \\
\hline $\begin{array}{l}\text { Pigment Specific Normalized } \\
\text { Difference }\end{array}$ & PSND & $\begin{array}{l}\operatorname{PSND}_{a}=\left(R_{800}-R_{675}\right) /\left(R_{800}+R_{675}\right) \\
\operatorname{PSND}_{b}=\left(R_{800}-R_{650}\right) /\left(R_{800}+R_{650}\right)\end{array}$ & Blackburn (1998) \\
\hline Eucalyptus Pigment Indexes & EPI & $C h l_{a, b}=a_{a, b} \times\left(R_{672} /\left(R_{550} \times R_{708}\right)\right)_{a, b}^{\beta}$ & Datt (1998) \\
\hline Summed Reflectance Index & SRI & $\begin{array}{l}S_{1}=\int_{700}^{750}\left(R_{\lambda} / R_{555}-1\right) d \lambda \\
S_{2}=\int_{700}^{750}\left(R_{\lambda} / R_{705}-1\right) d \lambda\end{array}$ & Gitelson and Merzlyak (1994) \\
\hline \multicolumn{4}{|l|}{ Red edge position } \\
\hline 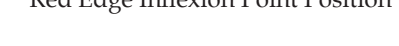 & ПРР & $K\left(\Lambda_{i}\right)=0$ & $\begin{array}{l}\text { Horler et al. (1983), Curran et al. (1995), Gitelson et al. (1996), } \\
\text { Kochubey and Kazantsev (2007) }\end{array}$ \\
\hline
\end{tabular}


Boochs et al., 1990). It was later shown that the reflectance derivative could exhibit several local maxima in the red edge area in measured (Gitelson et al., 1996) and simulated (le Maire et al., 2004) spectra. The nature of this multiple-peak feature is not well understood. Zarco-Tejada et al. (2003) suggested that the double-peak is due to steady-state fluorescence emission. Le Maire et al. (2004) showed that the double-peak can be simulated by the PROSPECT model by increasing the chlorophyll content alone, regardless of the values of other parameters. It can be also simulated by increasing the structure parameter alone if the total chlorophyll content exceeds $400 \mathrm{mg} \mathrm{cm}^{-2}$.

The potential to use fluorescence spectroscopy as a non-destructive method to detect plant stress was recognized in several early studies (e.g., Buschmann and Schrey, 1981; Chappelle et al., 1984; Lichtenthaler and Rinderle, 1988). Fluorescence emission maxima were observed at 440-450, 525-535, 680-685, and 735-740 nm (e.g., Richards et al., 2003) and related to components of photosynthesis and leaf pigments (e.g., Buschmann et al., 2000). Gitelson et al. (1999) used a ratio of fluorescence at $735 / 700 \mathrm{~nm}$ which provided an accurate prediction of chlorophyll content in intact leaves. Recent authors have continued to explore active (e.g., laser-induced) fluorescence (Corp et al., 2006; Richards et al., 2003) and solar-induced fluorescence (Zarco-Tejada et al., 2003; Dobrowski et al., 2005) to detect environmental stresses. Carter et al. (2004) measured solar-induced fluorescence in $10 \mathrm{~nm}$ bands at 690 and $760 \mathrm{~nm}$ using the Fraunhofer Line Depth Principle to detect stress, and more recently, Meroni and Colombo (2006) used very high resolution $(0.06 \mathrm{~nm})$ spectrometry at 687 and $760 \mathrm{~nm}$ to detect chlorophyll fluorescence in an oxygen band where solar irradiance is reduced.

\section{Detecting and quantifying foliar pigment composition in relation to ecological condition}

The concept of ecological convergence expresses the "economy of form" or the efficiency that particular sets of traits provide in exploiting limited environmental resources (Field et al., 1992). This concept implies that the cost of biochemical investments should be related to growth potential and thus better measurements of pigment distributions and concentrations could provide a basis for monitoring physiological and ecological processes. It is known that pigment composition varies with species and environmental conditions (e.g., Peñuelas et al., 1995a; Carter and Knapp, 1991; Asner et al., 2008). Deciduous species have leaves that are generally adapted for faster growth rates and higher photosynthetic capacity (e.g., higher chlorophyll and nitrogen concentrations) than needles in evergreen species where the cost of producing lower photosynthetic capacity foliage can be amortized over several years (Wright et al., 2004). Figure 5 illustrates differences in the amount and composition of photosynthetic pigments in leaves from a deciduous oak grown in the higher light environment of the savanna compared to leaves from the more closed canopy of the evergreen oak community (Ustin et al., 1993). Reflectance from the evergreen oak leaves is lower across the visible spectrum and the spectral shape is different. The total amount of pigments is lower in leaves from the evergreen oak and their relative proportions differ from the deciduous species. Note that small absorption features (at this presentation scale) are observed in these leaves near $585 \mathrm{~nm}, 620 \mathrm{~nm}$, and $650 \mathrm{~nm}$, suggesting that it may be possible to identify the basis for these features, particularly at the canopy level where absorption features are enhanced by transmission through multiple leaf layers (Allen and Richardson, 1968; Knipling, 1970; Curran, 1980; Stylinski et al., 2001; Roberts et al., 2004).
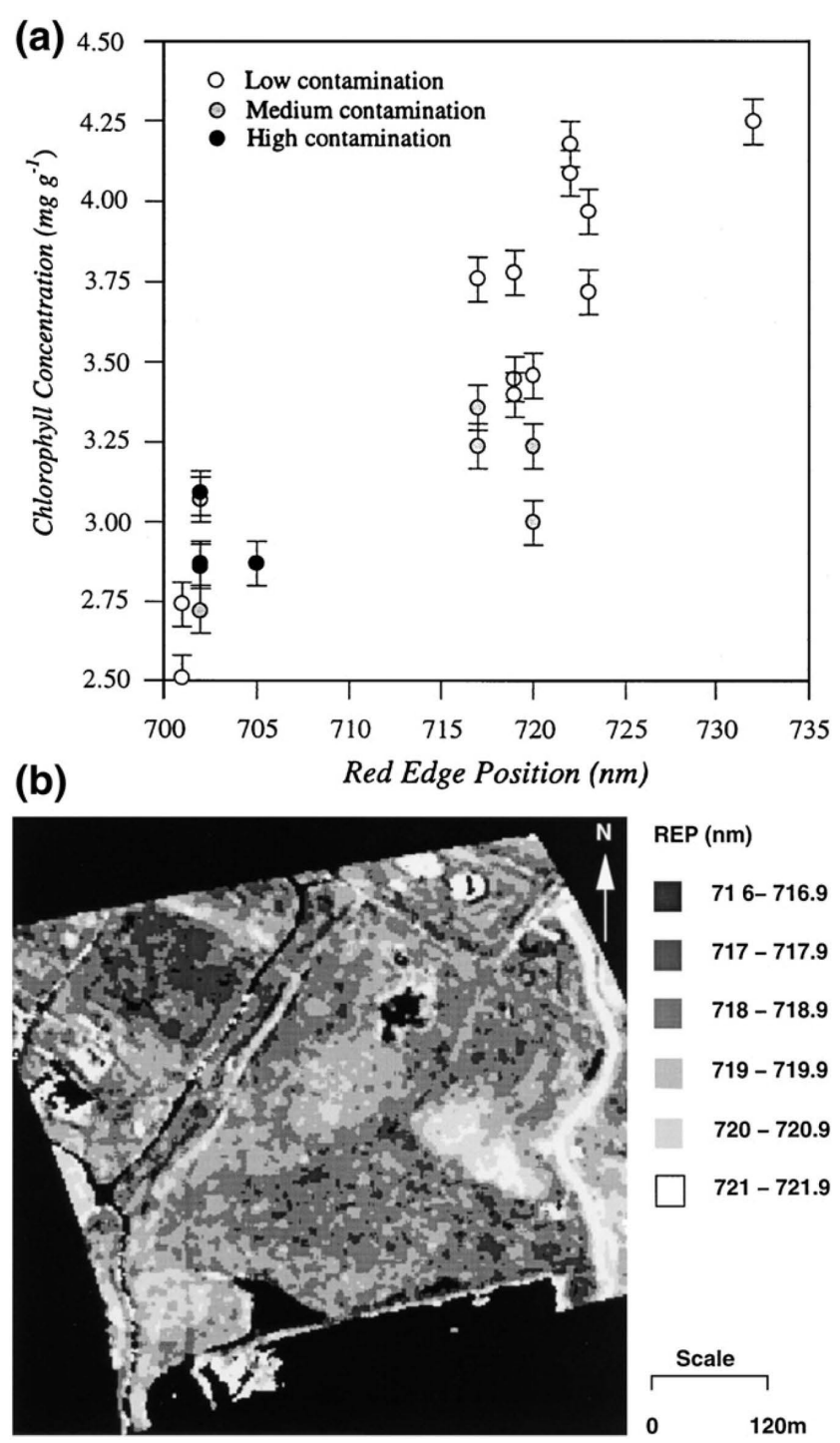

Figure 3. Correlation between the red-edge position (REP) and chlorophyll concentration (upper panel) of a grass canopy, Isle of Grain, Kent, United Kingdom for plot averages $(r=0.84, n=23)$. Error bars show the standard deviation of the chlorophyll determination. The airborne CASI hyperspectral image (lower panel) of the site illustrates spatial variation in REP response to oil contamination at the site. The grassland is reported to be relatively uniform with little variation in leaf area index, however REP indicates substantial differences in chlorophyll concentration (reproduced from Jago et al., 1999).

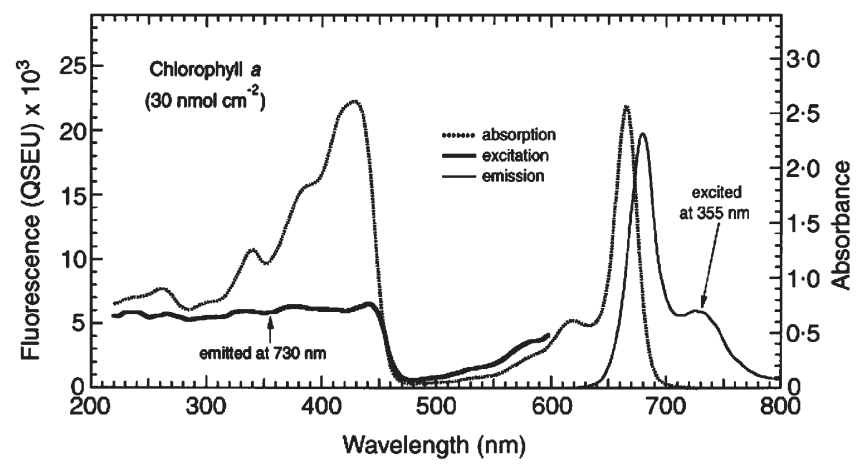

Figure 4. Comparison of absorption spectrum for pure chlorophyll a, its active fluorescence excitation and its emission spectrum (reproduced from Cerovic et al., 2002). 

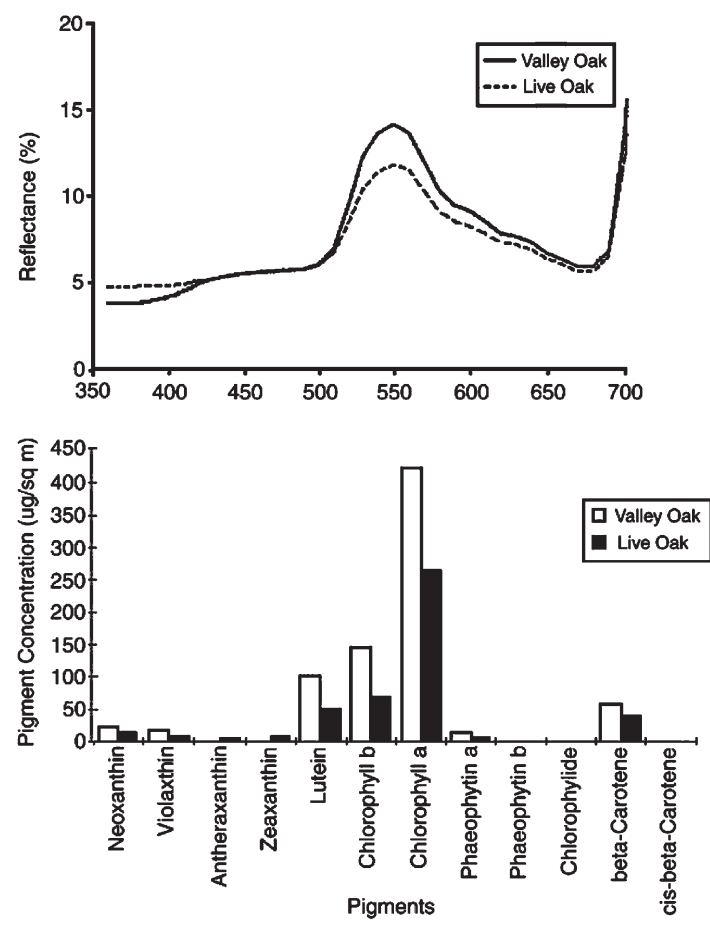

Figure 5. (left) Mean reflectance spectra of leaves from two species of California oaks the winter deciduous Quercus lobata (Valley Oak) and evergreen $Q$. agrifolia (Live Oak), measured in midsummer at Jasper Ridge Biological Preserve. (top) Mean pigment concentration and composition for these species (bottom). (reproduced from Ustin et al., 1993).

\section{Detection of foliar stress using the Photochemical Reflec- tance Index (PRI)}

Under high light, it is well established that xanthophyll cycle pigments function to prevent photooxidation of the reaction centers (Demmig-Adams \& Adams, 1996). Short-term changes in reflectance in response to the light environment are observed at $531 \mathrm{~nm}$ that detect reversible changes in the distribution of xanthophyll cycle pigments (violaxanthin is converted to zeaxanthin through the intermediate antheraxanthin under high light and reverts to violaxanthin under low light; Demmig-Adams, 1990). This is the basis for the photochemical reflectance index (PRI; Table 2), a normalized ratio of $531 \mathrm{~nm}$ to $570 \mathrm{~nm}$ developed by Gamon and colleagues (Gamon et al., 1990, 1992, 1993, 1997; Peñuelas et al., 1995a, 1997). The PRI, at the time of the NASA Accelerated Canopy Chemistry Program (ACCP), was shown to detect the transition to zeaxanthin in foliage exposed to high light intensities and this response is closely tied to photosynthetic activity (Gamon et al., 1990, 1992, 1993; Peñuelas et al., 1995a). The relationship between PRI and photosynthetic light-use efficiency has been explored at multiple scales (leaf to stand-level) in the years since this index was developed (e.g., Nichol et al., 2000; Gamon, 2001; Drolet et al., 2005; Nakaji et al., 2005). When the PRI is measured over longer time spans (seasons, years) or across species, variation appears to track relative composition of chlorophylls and carotenoids (e.g. Stylinski et al., 2001; Sims and Gamon, 2002).

\section{Detection of carotenoid pigments and anthocyanin pigments}

The red and yellow colors of autumn foliage are seen because of the change in photoperiod (toward short days/long nights) and/or low temperatures that initiate a senescence response in which chlorophyll pigments breakdown before the carotenoid pigments (e.g., lutein and $\beta$-carotene). Table 2 lists several wavelength specific indexes that have been used to estimate carotenoid pigment contents in foliage. Anthocyanins are red flavonoid pigments that are cytoplasmic and not associated with the chloroplast but they are often observed during environmental stresses (e.g., low or high temperatures) and during senescence (Schaberg et al., 2008). Anthocyanins are also common during the earliest stages leaf development before the photosystems are fully functional (Gamon \& Surfus, 1999). Like carotenoids, anthocyanins protect the photosynthetic system from excess light, particularly excess UV radiation (Merzlyak and Chivkunova, 2000; Gitelson et al., 2001), and may provide other functions, e.g., protection from herbivory and fungal pathogens (Close \& Beadle, 2003). These pigments have a single absorption maximum around $529 \mathrm{~nm}$ and can be detected by reflectance changes in the green region (Table 3); reflectance in the red-edge region does not vary with anthocyanin content and so the red edge can be used as a reference against which anthocyanin is determined (Curran et al., 1991; Neill and Gould, 1999; Gitelson et al., 2001, 2006).

\section{Development of spectral vegetation indexes for individual pigments}

Detection of individual pigments from reflectance data has been given less attention by the remote sensing community than total pigment measures, despite the importance of accessory pigments in light capture, photosystem protection, and in various growth and development functions. This lack is due to the difficulty in resolving the overlapping absorptions of individual pigments and their high degree of autocorrelation (Chappelle et al., 1992; Ramsey and Rangoonwala, 1995; Blackburn, 1998; Grossman et al., 1996). Nonetheless, because pigments have distinc-

Table 2. Spectral indexes developed as carotenoid indicators.

\begin{tabular}{|c|c|c|c|}
\hline Index & Short & Formula & Source \\
\hline Ratio Analysis of Reflectance Spectra & RARS & RARS $_{c}=R_{760} / R_{500}$ & Chappelle et al. (1992) \\
\hline Structure Insensitive Pigment Index & SIPI & $P S N D_{\mathrm{c}}=\left(R_{800}-R_{445}\right) /\left(R_{800}-R_{680}\right)$ & Peñuelas et al. (1995a), Sims and Gamon (2002) \\
\hline Pigment Specific Simple Ratio & PSSR & $P S S R_{c}^{c}=R_{800} / R_{500}$ & Blackburn (1998) \\
\hline Carotenoid Reflectance Index & CRI & $\begin{array}{l}C R I_{550}{ }^{c}=R_{510}{ }^{-1}-R_{550}{ }^{-1} \\
C R I_{700}=R_{510}{ }^{-1}-R_{700}{ }^{-1}\end{array}$ & Gitelson et al. (2002) \\
\hline Modified Carotenoid Reflectance Index & $\mathrm{mCRI}$ & $\begin{array}{l}m C R I_{G}=\left(R_{510-520}{ }^{-1}-R_{560-570}{ }^{-1}\right) \times R_{N I R} \\
m C R I_{E E}=\left(R_{510-520}{ }^{-1}-R_{690-710^{-1}}\right) \times R_{N I R}\end{array}$ & Gitelson et al. (2006) \\
\hline Photochemical Reflectance Index & PRI & $P R I=\left(R_{531}-R_{570}\right) /\left(R_{531}+R_{570}\right)$ & Gamon et al. $(1990,1992,1997)$ \\
\hline Eucalyptus Pigment Indexes & EPI & Car $=a \times\left(R_{672} /\left(R_{550} \times R_{708}\right)\right)^{\beta}$ & Datt (1998) \\
\hline
\end{tabular}

Table 3. Spectral indexes developed as anthocyanin indicators.

\begin{tabular}{|c|c|c|c|}
\hline Index & Short & Formula & Source \\
\hline $\begin{array}{l}\text { Anthocyanin Reflectance Index } \\
\text { Modified Anthocyanin Reflectance Index } \\
\text { Red:Green Ratio }\end{array}$ & $\begin{array}{l}\text { ARI } \\
\text { mARI } \\
\text { RGR }\end{array}$ & $\begin{array}{l}A R I=R_{550}^{-1}-R_{700}^{-1} \\
m A R I=\left(R_{530-570}^{-1}-R_{690-710}^{-1}\right) \times R_{N I R} \\
R G R=R_{R} / R_{G}\end{array}$ & $\begin{array}{l}\text { Gitelson et al. (2001) } \\
\text { Gitelson et al. (2006) } \\
\text { Gamon and Surfus (1999), Sims and Gamon (2002) }\end{array}$ \\
\hline
\end{tabular}


tive absorption spectra depending on their molecular structure and local chemical environment, there is a potential to measure these properties using reflectance spectroscopy. The challenge is to properly account for the multiple factors influencing the retrieved signal. While many models relate chlorophyll content to reflectance (e.g., Gitelson and Merzlyak, 1994; Sims and Gamon, 2002; Richardson et al., 2002; Gitelson et al., 2003; le Maire et al., 2004) and some are robust in chlorophyll prediction, only few models support retrieval of anthocyanins and carotenoids (e.g., Gitelson et al., 2001, 2002; Sims and Gamon, 2002).

There are a few examples in the literature where chlorophyll a and chlorophyll $\mathrm{b}$ have been separately assessed from reflectance data using empirical models. Among the first, Chappelle et al. (1992) and Blackburn (1999) used band ratios to quantify chlorophyll b. Curran et al. (2001) demonstrated retrieval of foliar chlorophyll $b$ using the continuum removal method of Kokaly and Clark (1999). Pinzón et al. (1998) used a hierarchical singular value decomposition method to quantify biochemical constituents in intact leaf samples, where total sample variance was broken down into smaller ranges of variation using a series of weighting vectors.

One explanation for past inconsistencies in separating and quantifying different pigments is that their absorption spectra overlap, thus simple methods do not account for the interacting effects of multiple pigments and fail across a range of taxa (e.g., Figure 1) or where the conditions are outside the range that these empirical methods were tested and calibrated. In other cases, indexes that seem to provide consistent results at the leaf level fail or become inconsistent at the canopy or stand levels, in part due to the complexities of the three-dimensional structure and multiple scattering in intact leaves. Additionally, despite progress at the leaf level, no analytical model today has accounted for the quantification of anthocyanin and carotenoid contents at the canopy or stand scales.

\section{Development of multiple pigment models}

The first model to estimate multiple pigment contents was developed by Gitelson and colleagues (Gitelson et al., 2003, 2006). They proposed a conceptual model based on the relationship between the reciprocal of reflectance, a property closely related to the infinite reflectance of a leaf, and its inherent optical properties, absorption and backscattering coefficients. They then modeled pigment absorption using three narrow spectral bands, where reflectance in the first band $\left(\lambda_{1}\right)$ is maximally sensitive to absorption by the pigment of interest but is also affected by absorptions from other pigments and variability in backscattering (Figure 6). These extraneous effects are removed by identifying a second band $\lambda_{2}$ where the other pigments absorb but the pigment of interest has little effect and where backscattering is relatively unchanged from $\lambda_{1}$. Then a third spectral band $\lambda_{3}$ is selected where backscattering controls the overall reflectance. Combining these three bands allows the pigment content $\left(\mathrm{C}_{\text {pigment }}\right)$ to be estimated:

$$
C_{\text {pigment }} \propto\left[R^{-1}\left(\lambda_{1}\right)-R^{-1}\left(\lambda_{2}\right)\right] \times R\left(\lambda_{3}\right) \text {. }
$$

The spectral regions used in the model were tuned with respect to the pigment of interest and the optical characteristics of the leaves studied. The optimal bands for each pigment (chlorophyll, carotenoids and anthocyanins) retrieval are determined by performing the calibration for a continuous range from 400$800 \mathrm{~nm}$, isolating one band at a time, and choosing each of the 3 bands according to a minimal root mean square error (RMSE) (Figure 6). For total chlorophyll content retrieval optimum $\lambda_{1}$ was found in either the green $(540-560 \mathrm{~nm})$ or red edge (700$730 \mathrm{~nm}$ ) range, and $\lambda_{2}=\lambda_{3}$ was in the NIR beyond $760 \mathrm{~nm}$ (Figure 6a, Gitelson et al., 2003, 2006).

Zur et al. (2000) and Gitelson et al. (2002) identified a spectral band near $510 \mathrm{~nm}$ that was sensitive to total content of carotenoids and used it in a three-band model to estimate the total carotenoid content (Figure 6b, Gitelson et al., 2002, 2006). They applied this model to retrieve anthocyanin, developing an Anthocyanin Reflectance Index (Figure 6c, Gitelson et al., 2001, 2006). In anthocyanin-free leaves, both the green and the red edge bands can be used as $\lambda_{1}$ for chlorophyll estimation and as $\lambda_{2}$ for carotenoid estimation (Figure $6 \mathrm{~b}$ ). Thus, only four spectral bands are required to

(a)
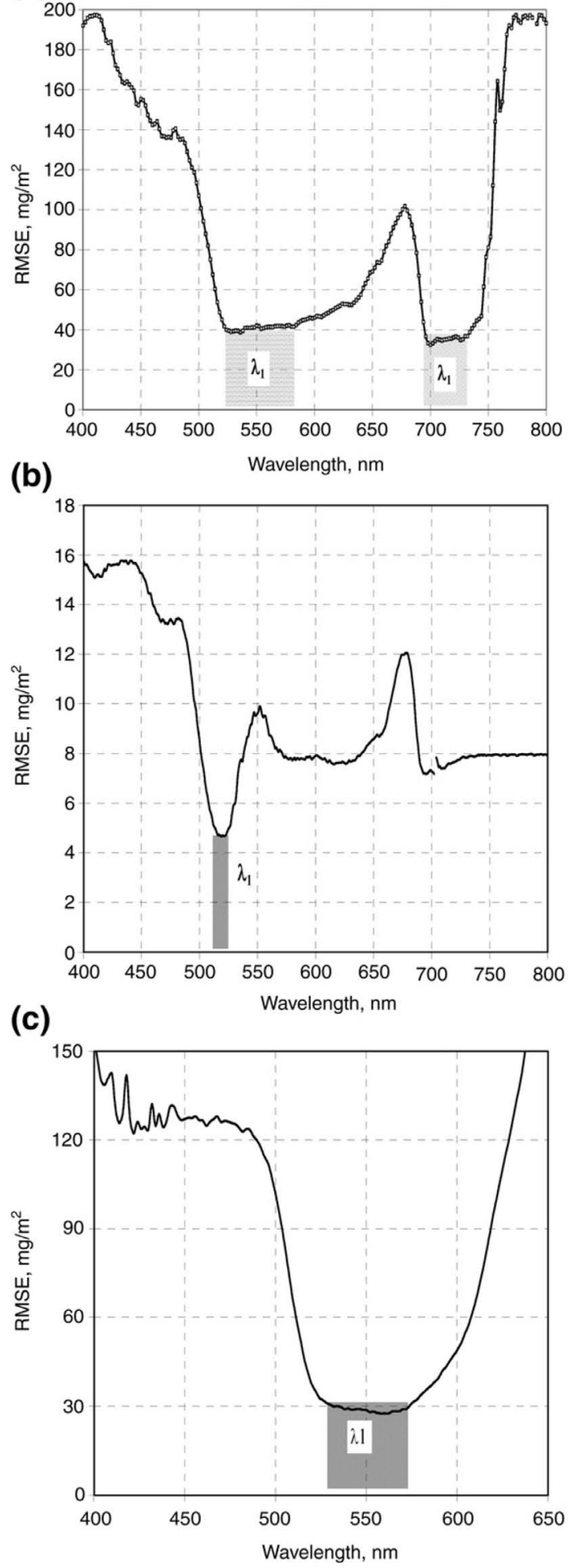

Figure 6. Optimal positions of spectral band $\lambda_{1}$ of the model $\left[R\left(\lambda_{1}\right)^{-1}\right.$ $\left.-R\left(\lambda_{2}\right)^{-1}\right] \times R\left(\lambda_{3}\right)$ for retrieval of (A) total chlorophyll, (B) carotenoid, and $(C)$ anthocyanin content from reflectance spectra (reproduced from Gitelson et al., 2006). 
(a)

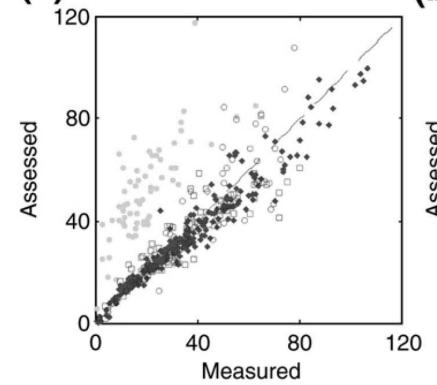

(b)

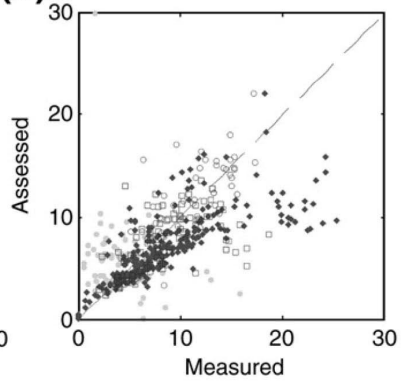

Figure 7. Predicted and measured total chlorophyll (left) and total carotenoid (right) pigments based on an inversion of the PROSPECT 5 model (reproduced from Feret et al., 2008) using leaves from four sources: (• LOPEX (Hosgood et al., 1994) $\square$ CALMIT (Gitelson et al., 2002] and [Gitelson et al., 2003) - ANGERS (INRA, France) ○ HAWAI (Asner \& Martin, 2008).

retrieve three pigment contents: 510-520 nm (carotenoids), 540$560 \mathrm{~nm}$ (anthocyanins), 700-730 nm (total chlorophyll) and NIR in the range $760-800 \mathrm{~nm}$. This model produced accurate estimates of the total chlorophylls, carotenoids, and anthocyanin contents, explaining more than $91 \%, 70 \%$, and $93 \%$ of the variance, respectively (Gitelson et al., 2006). However, the model for carotenoids retrieval was found to be species specific.

\section{Leaf radiative transfer models}

Physically based RT models have the potential to produce more accurate and consistent predictions of pigment interactions because they are based in physics and use the full spectrum rather than individual bands and therefore, do not require calibration each time they are used. However, RT model predictions of the optical properties of monocot or dicot leaves or needles depend on how well understood all processes affecting reflectance are and how they are accounted for in the models. Although they have potential to predict pigment content more consistently and accurately than empirical methods, they require more input parameters, which if wrong, result in poor model performance. Thus, empirical models can be more accurate than physical models if the components are improperly modeled or the input data is wrong.

Several leaf models, e.g., PROSPECT (Leaf Optical Properties Spectra, Jacquemoud and Baret, 1990), LIBERTY (Leaf Incorporating Biochemistry Exhibiting Reflectance and Transmittance Yields, Dawson et al., 1998), LEAFMOD (Leaf Experimental Absorptivity Feasibility MODel, Ganapol et al., 1998), and SLOP (Stochastic model for Leaf Optical Properties, Maier et al., 1999; Maier, 2000), have been used since the 1990s to estimate total chlorophyll concentration (see review in Ustin et al., 2004). Instead of modeling multiple pigments, RT models currently assume that leaf pigments are entirely composed of chlorophyll and that the horizontal and vertical distribution of these absorbers is homogeneous within foliar tissues.

Characterization of in situ absorption coefficients for xanthophylls, carotenes and even chlorophyll $\mathrm{b}$ need to be added to leaf RT models to estimate individual pigments. This will require defining in vivo absorption coefficients for all individual pigments but also better knowledge of the spectral variation of the refractive index of leaves, information that is not currently available and which may vary depending upon the chemical environment within the leaf. Maier et al. (1999) and Berdnik and Mukhamed'yarov (2001) followed this approach and utilized separate in vitro absorption spectra of chlorophyll $a, b$ and several carotenoids in developing their leaf optical prop- erties model. An advanced version of the PROSPECT model (PROSPECT 5) that can discriminate chlorophylls from total carotenoids has been developed (Feret et al., 2008). This required a long phase of calibration using datasets carefully selected to cover a wide range of leaf photosynthetic pigments. Feret et al. (2008) showed that some improvements in prediction of leaf reflectance, on the order of $5 \%$ in the visible, could be made by better characterization of pigment contributions. Figure 7 shows the comparison between measured and PROSPECT- 5 predicted total chlorophyll (left) and total carotenoid (right) contents from leaves representing a wide range of ecological conditions and communities, from mesic and semiarid temperate forests, shrublands, and agriculture, to subtropical and tropical systems.

The fact that light can be propagated through leaves without encountering foliar pigments, for instance in veins, is a phenomenon known as the sieve effect which has been accounted for in RT models to better interpret absorption spectra of leaves (Latimer, 1983; McClendon and Fukshansky, 1990). Additionally, bifacial leaves with different chlorophyll content in the palisade and spongy mesophylls can be simulated using the KubelkaMunk theory applied to two or more stacked layers (Yamada and Fujimura, 1991; Richter and Fukshansky, 1996). With this added level of physical detail being built into RT leaf reflectance models, it is likely that it will lead to better characterization of individual pigments.

A recent European program to develop methods to detect leaf and canopy fluorescence has produced a new model, FluorMOD, with linked leaf and canopy models to detect the effects of steady-state solar-induced chlorophyll fluorescence (ZarcoTejada et al., 2006; Middleton et al., 2008).

\section{Challenges in imaging spectroscopy of vegetation pigments}

The application of narrow-band spectral methods for pigment detection to airborne and spaceborne spectrometers has been the intended goal of much of the leaf-level research since the time of the ACCP program that Dr. Goetz headed. Fieldand laboratory-based spectroscopy of plant pigments has had a long period of development and today, a large number of studies have explored the detection of pigments in many leaf types originating from a wide range of ecosystems and using a wide range of methods. The use of airborne and space-based imaging spectrometers to detect and map foliar pigments is still relatively new (e.g., Collins, 1978; Rock et al., 1988; Zarco-Tejada and Miller, 1999). These examples highlight the potential contribution of imaging spectroscopy for detecting and quantifying foliar pigments from imaging spectroscopy to studies of canopy physiology and ecology. At this time, current methods have not delivered unambiguous results and operational methods for this level of biochemical retrieval. Advances in algorithm development as highlighted above indicate that numerous challenges remain to be solved before pigment concentrations can be routinely retrieved from space. Imaging spectrometer design is a key issue in the quest for more quantitative approaches to identification of pigments. This will require an instrument that has high spectral resolution, $\sim 3-5 \mathrm{~nm}$ to measure pigment details but which has good signal to noise characteristics of up to 1000:1 in the visible and infrared region. The fidelity of the sensor, which includes signal-to-noise performance, uniformity of the image, and stability of the electronics all affect the outcome of a canopy chemical analysis. Instruments must be calibrated in terms of wavelength (i.e., avoiding keystone and smile) and have radiometric stability.

A good example of current technological capability is found by looking at the evolution of the Jet Propulsion Laboratory's 
Advanced Visible Infared Imaging Spectrometer (AVIRIS) program, which started under the leadership of Dr. A.F.H. Goetz in 1982. In the early 1990s, AVIRIS signal-to-noise ratio was in the 10-100 range depending upon wavelength region (Vane et al., 1993). Since then, AVIRIS has evolved, through major upgrades and constant hardware and software adjustment, to provide spectra with effective signal-to-noise performances of many $100 \mathrm{~s}$ to $1000 \mathrm{~s}$ (Green et al., 2003). The resolution, stability, and sensitivity of the sensor technology bears squarely upon the state of hyperspectral algorithm development. With the high fidelity of AVIRIS today and a few other sensors, it is possible to use physically-based methods, such as canopy RT models, to explore spectra in some detail. Thus, advances in modeling pigments at the leaf level can be incorporated into models suitable for imaging spectrometers. However, since most remote mapping of ecosystems will be at canopy level, solid coupling of leaf radiative transfer models with canopy scale models will be key to successful retrieval of multiple pigments from air- or spaceborne spectrometers. At canopy scale, the simultaneous assessment of canopy heterogeneity as well as pigments will require a better representation of clumped and sparse canopies in coupled RT models. Future sensors, having capabilities similar to the proposed NASA HyspIRI mission and the German EnMap program (Kaufmann et al., 2006), will eventually deliver spectroscopic measurements of sufficiently high fidelity to advance the mapping of canopy pigments and other chemicals.

\section{Acknowledgments}

This paper is dedicated to Dr. Alexander Goetz, who as chair of the NASA HIRIS Canopy Chemistry Program stimulated much of the early research on plant pigments and continues to impact research today, through the use of plant biochemical databases and various analytical approaches that developed during this program. His vision of imaging spectrometry has allowed the development of techniques and measurements that have linked a detailed understanding of plant physiological functioning with optical properties, and provided the opportunity to study biological processes from the leaf to planetary scales. S.U. wishes to thank the Department of Biological Science, Victoria University, Wellington, New Zealand for providing space and support while this paper was written during her sabbatic leave and support from the USDA Agricultural Experiment Station Hatch program, \#5661-H "Identification of canopy chemistry using reflectance and imaging spectroscopy."

\section{References}

Allen and Richardson, 1968 W. A. Allen and A. J. Richardson, Interaction of light with a plant canopy, Journal of the Optical Society of America 58 (1968), pp. 1023-1028.

Anderson et al., $1988-$ J. Anderson, W. Chow, and D. Godchild, Thylakoid membrane organisation in sun/shade acclimation, Australian Journal of Plant Physiology 15 (1988), pp. 11-26.

Aoki et al., $1980 \rightarrow$ M. Aoki, K. Yabuki, and T. Totsuka, Remote sensing of the physiological functions of plants by infrared color aerial photography. I. Relation between leaf reflectivity ratio, bi-band ratio and photosynthetic function of leaves in several woody plants, Research Report from the National Institute for Environmental Studies 11 (1980), pp. 225-237.

Aoki et al., 1986 M. Aoki, K. Yabuki, T. Totsuka, and M. Nishida, Remote sensing of chlorophyll content of leaf (I) Effective spectral reflection characteristics of leaf for the evaluation of chlorophyll content in leaves of Dicotyledons, Environmental Control in Biology 24 (1986), pp. 21-26.

Arnold et al., 2002 L. Arnold, S. Gillet, O. Lardiere, P. Riaud, and J. Schneider, A test for the search for life on extrasolar planets, Astronomy and Astrophysics 392 (2002), pp. 231-237.

Asner et al., 2005 G. P. Asner, A. J. Elmore, R. Flint, R. Hughes, A. S. Warner, and P. M. Vitousek, Ecosystem structure along bioclimatic gradients in Hawai'i from imaging spectroscopy, Remote Sensing of Environment 96 (2005), pp. 497-508.

Asner et al., 2008 G. P. Asner, M. O. Jones, R. E. Martin, D. E. Knapp, R. F. Hughes, and R. Flint, Remote sensing of native and invasive species in Hawaiian forests, Remote Sensing of Environment 112 (2008), pp. 1912-1926.

Asner and Martin, 2008 G. P. Asner and R. E. Martin, Airborne spectranom- ics: Mapping canopy chemical and taxonomic diversity in tropical ecosystems, Frontiers in Ecology and the Environment 7 (2008), doi: 10. 1890/070152.

Asrar et al., 1984 G. Asrar, H. Fuchs, E. T. Kanemasu, and J. L. Hatfield, Estimating absorbed photosynthetic radiation and leaf-area index from spectral reflectance in wheat, Agronomy Journal 76 (1984), pp. 300-306.

Belanger, $1990>$ M. J. Belanger, A seasonal perspective of several leaf developmental characteristics as related to the red edge of plant leaf reflectance, Master of Science Thesis, Faculty of Graduate Studies, York University, North York (Ontario, Canada, 1990), 110 pp.

Berdnik and Mukhamed'yarov, $2001 \vee$ V. V. Berdnik and R. D. Mukhamed'yarov, Radiation transfer in plant leaves, Optics and Spectroscopy 90 (2001), pp. 580-591.

Blackburn, 1998 G. A. Blackburn, Quantifying chlorophylls and carotenoids at leaf and canopy scales: An evaluation of some hyperspectral approaches, Remote Sensing of Environment 66 (1998), pp. 273-285.

Blackburn, 1999 G. A. Blackburn, Relationships between spectral reflectance and pigment concentrations in stacks of deciduous broadleaves, Remote Sensing of Environment 70 (1999), pp. 224-237.

Blackburn, 2007 G. A. Blackburn, Hyperspectral remote sensing of plant pigments, Journal of Experimental Botany 58 (2007), pp. 855-867.

Boochs et al., $1990>$ F. Boochs, G. Kupfer, K. Dockter, and W. Kuhbauch, Shape of the red edge as vitality indicator for plants, International Journal of Remote Sensing 11 (1990), pp. 1741-1753.

Buschmann et al., $2000>$ C. Buschmann, G. Langsdorf, and H. K. Lichtenthaler Imaging of the blue, green, and red fluorescence emission of plants: An overview, Photosynthetica 38 (2000), pp. 483-491.

Buschmann and Nagel, $1993 \rightarrow$ C. Buschmann and E. Nagel, In vivo spectroscopy and internal optics of leaves as basis for remote-sensing of vegetation, International Journal of Remote Sensing 14 (1993), pp. 711-722.

Buschmann et al., 1994 C. Buschmann, E. Nagel, K. Szabo, and L. Kocsanyi, Spectrometer for fast measurements of in vivo reflectance, absorptance, and fluorescence in the visible and near-infrared, Remote Sensing of Environment 48 (1994), pp. 18-24.

Buschmann and Schrey, $1981 \rightarrow C$. Buschmann and H. Schrey, Fluorescence induction kinetics of green and etiolated leaves by recording the complete invivo emissions spectra, Photosynthesis Research 1 (1981), pp. 233-241.

Carter, $1994 \rightarrow$ G. A. Carter, Ratios of leaf reflectances in narrow wavebands as indicators of plant stress, International Journal of Remote Sensing 15 (3) (1994), pp. 697-703.

Carter et al., 2004 G. A. Carter, A. Freedman, P. L. Kebabian, and H. E. Scott, Use of a prototype instrument to detect short-term changes in solar-excited leaf fluorescence, International Journal of Remote Sensing 25 (2004), pp. 1779-1784.

Carter and Knapp, 1991 - G. A. Carter and A. K. Knapp, Leaf optical properties in higher plants: Linking spectral characteristics to stress and chlorophyll concentration, American Journal of Botany 88 (1991), pp. 677-684.

Carter and Spiering, 2002 G. A. Carter and B. A. Spiering, Optical properties of intact leaves for estimating chlorophyll concentration, Journal of Environmental Quality 31 (2002), pp. 1424-1432

Cerovic et al., 2002 Z. G. Cerovic, A. Ounis, A. Cartelat, G. Latouche, Y. Goulas, and S. Meyer et al., The use of chlorophyll fluorescence excitation spectra for the non-destructive in situ assessment of UV-absorbing compounds in leaves, Plant, Cell and Environment 25 (2002), pp. 1663-1676.

Chang and Collins, 1983 S. H. Chang and W. Collins, Confirmation of the airborne biogeophysical mineral exploration technique using laboratory methods, Economic Geology 78 (1983), pp. 723-726.

Chappelle et al., 1992 E. W. Chappelle, M. S. Kim, and J. E. McMurtrey III, Ratio analysis of reflectance spectra (RARS): An algorithm for the remote estimation of the concentrations of chlorophyll a, chlorophyll b, and carotenoids in soybean leaves, Remote Sensing of Environment 39 (1992), pp. 239-247.

Chappelle et al., 1984 E. W. Chappelle, J. E. McMurtrey, F. M. Wood, and W. W. Newcomb, Laser-induced fluorescence of green plants. 2. LIF caused by nutrient deficiencies in corn, Applied Optics 23 (1984), pp. 139-142.

Cho and Skidmore, 2006 M. A. Cho and A. K. Skidmore, A new technique for extracting the red edge position from hyperspectral data: The linear extrapolation method, Remote Sensing of Environment 101 (2006), pp. 181-193.

Close and Beadle, $2003 \rightarrow$ D. C. Close and C. L. Beadle, The ecophysiology of foliar anthocyanin, Botanical Review 69 (2003), pp. 149-161.

Collins, 1978 W. Collins, Remote sensing of crop type and maturity, Photogrammetric Engineering and Remote Sensing 44 (1978), pp. 43-55.

Corp et al., 2006 L. A. Corp, E. M. Middleton, J. E. McMurtrey, P. K. E. Campbell, and L. M. Butcher, Fluorescence sensing techniques for vegetation assessment, Applied Optics 45 (2006), pp. 1023-1033.

Curran, $1980 \triangleright$ P. J. Curran, Multispectral remote sensing of vegetation amount, Progress in Physical Geography 4 (1980), pp. 315-341.

Curran et al., 1991 P. J. Curran, J. L. Dungan, B. A. Macler, and S. E. Plummer, The effect of a red pigment on the relationship between red edge and chlorophyll concentration, Remote Sensing of Environment 35 (1991), pp. 69-76.

Curran et al., 2001 P. J. Curran, J. L. Dungan, and D. L. Peterson, Estimating the foliar biochemical concentration of leaves with reflectance spectrometry, Remote Sensing of Environment 76 (2001), pp. 349-359.

Curran et al., 1995 P. J. Curran, W. R. Windham, and H. L. Gholz, Exploring the relationship between reflectance red edge and chlorophyll concentration in slash pine leaves, Tree Physiology 15 (1995), pp. 203-206.

Curtiss and Ustin, 1989 B. Curtiss and S. L. Ustin, Parameters affecting reflectance of coniferous forests in the region of chlorophyll pigment absorption, 
IGARSS '89 Proceedings of the International Geoscience and Remote Sensing Symposium, Vancouver, BC, Canada. July, 1989. IEEE 89CH2768-0 vol. 4 (1989), pp. 2633-2636.

Datt, 1998 B. Datt, Remote sensing of chlorophyll a, chlorophyll b, chlorophyll $\mathrm{a}+\mathrm{b}$, and total carotenoid content in Eucalyptus leaves, Remote Sensing of Environment 66 (1998), pp. 111-121.

Datt, 1999 Datt, B. (1999). Visible/near infrared reflectance and chlorophyll content in Eucalyptus leaves. International Journal of Remote Sensing, 20, 2741-2759.

Dawson et al., 1998 T. P. Dawson, P. J. Curran, and S. E. Plummer, LIBERTY - modeling the effects of leaf biochemical concentration on reflectance spectra, Remote Sensing of Environment 65 (1998), pp. 50-60.

Deering, 1978 Deering, D. W. (1978). Rangeland reflectance characteristics measured by aircraft and spacecraft sensors. Ph. D. diss. Texas A\&M Univ., College Station. 338p.

Demmig-Adams, 1990 B. Demmig-Adams, Carotenoids and photoprotection in plants: A role for the xanthophyll zeaxanthin, Biochemica and Biophysica Acta 1020 (1990), pp. 1-24.

Demmig-Adams and Adams, 1996 B. Demmig-Adams and W. W. Adams, The role of xanthophyll cycle carotenoids in the protection of photosynthesis, Trends in Plant Science 1 (1996), pp. 20-26.

Dobrowski et al., $2005 \triangleright$ S. Z. Dobrowski, J. C. Pushnik, P. J. Zarco-Tejeda, and S. L. Ustin, Simple reflectance indices track heat and water stress-induced changes in steady-state chlorophyll fluorescence at the canopy scale, Remote Sensing of Environment 97 (2005), pp. 403-414.

Drolet et al., 2005 G. G. Drolet, K. F. Huemmrich, F. G. Hall, E. M. Middleton, T. A. Black, and A. G. Barr et al., A MODIS-derived photochemical reflectance index to detect interannual variations in the photosynthetic lightuse efficiency of a boreal deciduous forest, Remote Sensing of Environment $\mathbf{9 8}$ (2005), pp. 212-224.

Du et al., 1998 H. Du, R. C. A. Fuh, J. Li, L. A. Corkan, and J. S. Lindsey, PhotochemCAD: A computer-aided design and research tool in photochemistry, Photochemistry and Photobiology 68 (1998), pp. 141-142.

Feret et al., 2008 J.-B. Feret, C. François, G. P. Asner, A. A. Gitelson, R. E. Martin, L. P. R. Bidel, S. L. Ustin, G. le Maire, and S. Jacquemoud, PROSPECT4 and 5: Advances in the leaf optical properties model separating photosynthetic pigments. Remote Sensing of Environment, 112 (2008), 3030-3043.

Field et al., 1992 - C. B. Field, F. S. Chapin III, P. A. Matson, and H. A. Mooney, Responses of terrestrial ecosystems to the changing atmosphere: A resourcebased approach, Annual Review of Ecology and Systematics 23 (1992), pp. 201-235.

Gamon et al., 1990 J. A. Gamon, C. B. Field, W. Bilger, O. Björkman, A. L. Fredeen, and J. Peñuelas, Remote sensing of the xanthophyll cycle and chlorophyll fluorescence in sunflower leaves and canopies, Oecologia 85 (1990), pp. 1-7.

Gamon et al., 1993 J. A. Gamon, I. Filella, and J. Peñuelas, The dynamic $531 \mathrm{~nm}$ reflectance signal: A survey of twenty angiosperm species. In: H. Y. Yamamoto and C. M. Smith, Editors, Photosynthetic Responses to the Environment, Rockville American Society of Plant Physiologists (1993), pp. 172-177.

Gamon et al., 1992 - J. A. Gamon, J. Peñuelas, and C. B. Field, A narrow waveband spectral index that tracks diurnal changes in photosynthetic efficiency, Remote Sensing of Environment 41 (1992), pp. 35-44.

Gamon et al., 1997 J. A. Gamon, L. Serrano, and J. S. Surfus, The photochemical reflectance index: An optical indicator of photosynthetic radiation use efficiency across species, functional types, and nutrient levels, Oecologia 112 (1997), pp. 492-501.

Gamon and Surfus, 1999 J. A. Gamon and J. S. Surfus, Assessing leaf pigment content and activity with a reflectometer, New Phytologist 143 (1999), pp. 105-117.

Gamon, 2001 Gamon, J. A., Field, C. B., Fredeen, A. L. \& Thayer, S. (2001). Assessing photosynthetic downregulation in sunflower stands with an optically-based model. Photosynthesis Research, 67, 113-125.

Ganapol et al., 1998 B. Ganapol, L. Johnson, P. Hammer, C. Hlavka, and D. Peterson, LEAFMOD: A new within-leaf radiative transfer model, Remote Sensing of Environment 6 (1998), pp. 182-193.

Gates et al., 1965 D. M. Gates, H. J. Keegan, J. C. Schleter, and V. R. Weider, Spectral properties of plants, Applied Optics 4 (1965), pp. 11-20.

Gitelson et al., 1999 A. A. Gitelson, C. Buschmann, and H. K. Lichtenthaler, The chlorophyll fluorescence ratio R735/F700 as an accurate measure of the chlorophyll content in plants, Remote Sensing of Environment 69 (1999), pp. 296-302.

Gitelson et al., $2003 \rightarrow$ A. A. Gitelson, U. Gritz, and M. N. Merzlyak, Relationships between leaf chlorophyll content and spectral reflectance and algorithms for non-destructive chlorophyll assessment in higher plant leaves, Journal of Plant Physiology 160 (2003), pp. 271-282.

Gitelson et al., 2006 A. A. Gitelson, G. P. Keydan, and M. N. Merzlyak, Threeband model for noninvasive estimation of chlorophyll, carotenoids, and anthocyanin contents in higher plant leaves, Geophysical Research Letters 33 (2006), p. L11402.

Gitelson and Merzlyak, 1994 A. A. Gitelson and M. N. Merzlyak, Quantitative estimation of chlorophyll-a using reflectance spectra-experiments with autumn chestnut and maple leaves, Journal of Photochemistry and Photobiology. B, Biology 22 (1994), pp. 247-252.

Gitelson and Merzlyak, 1997 A. A. Gitelson and M. N. Merzlyak, Remote estimation of chlorophyll content in higher plant leaves, International Journal of Remote Sensing 18 (1997), pp. 2691-2697.

Gitelson et al., 2001 A. A. Gitelson, M. N. Merzlyak, and O. B. Chivkunova, Optical properties and nondestructive estimation of anthocyanin content in plant leaves, Photochemistry and Photobiology 74 (2001), pp. 38-45.
Gitelson et al., 2002 A. A. Gitelson, Y. Zur, O. B. Chivkunova, and M. N. Merzlyak, Assessing carotenoid content in plant leaves with reflectance spectroscopy, Photochemistry and Photobiology 75 (2002), pp. 272-281.

Gitelson and Merzlyak, 1996 A. Gitelson and M. Merzlyak, Signature analysis of leaf reflectance spectra: Algorithm development for remote sensing of chlorophyll, Journal of Plant Physiology 148 (1996), pp. 495-500.

Gitelson et al., 1996 A. Gitelson, M. Merzlyak, and H. Lichtenthaler, Detection of red edge position and chlorophyll content by reflectance measurements near 700 nm, Journal of Plant Physiology 148 (1996), pp. 501-508.

Govindjee and Krogmann, 2004 Govindjee and D. Krogmann, Discoveries in oxygenic photosynthesis (1727-2003): A perspective, Photosynthesis Research 80 (2004), pp. 15-57.

Green et al., $2003 \rightarrow$ R. O. Green, B. E. Pavri, and T. G. Chrien, On-orbit radiometric and spectral calibration characteristics of EO-1 Hyperion derived with an underflight of AVIRIS and in situ measurements at Salar de Arizaro, Argentina, IEEE Transactions on Geoscience and Remote Sensing 41 (2003), pp. 1194-1203.

Grossman et al., 1996 Y. L. Grossman, S. L. Ustin, E. Sanderson, J. Jacquemoud, G. Schmuck, and J. Verdebout, Critique of stepwise multiple linear regression for the extraction of leaf biochemistry information from leaf reflectance data, Remote Sensing of Environment 56 (1996), pp. 182-193.

Hoque and Hutzler, $1992 \checkmark$ E. Hoque and P. J. S. Hutzler, Spectral blue shift of red edge monitors damage class of beech trees, Remote Sensing of Environment 39 (1992), pp. 81-84.

Horler et al., $1983 \longrightarrow$ D. N. Horler, M. Dockray, and J. Barber, The red edge of plant leaf reflectance, International Journal of Remote Sensing 4 (1983), pp. 273-288.

Hosgood et al., 1994 B. Hosgood, S. Jacquemoud, G. Andreoli, J. Verdebout, G. Pedrini, and G. Schmuck, Leaf Optical Properties EXperiment 93 (LOPEX93), European Commission- Joint Research Centre, Ispra (Italy), EUR 16095 EN (1994) 20 pp. ; http://www-gvm.jrc.it/stars/lopex.htm

Jacquemoud and Baret, $1990>$ S. Jacquemoud and F. Baret, PROSPECT: A model of leaf optical properties, Remote Sensing of Environment 34 (1990), pp. $75-91$.

Jago et al., 1999 Jago, R. A., Cutler, M. E. J., \& Curran, P. J. (1999). Estimating Canopy Chlorophyll Concentration from Field and Airborne Spectra. Remote Sensing of Environment, 68, 217-224.

Kaufmann et al., 2006 H. Kaufmann, K. Segl, S. Chabrillat, S. Hofer, T. Stuffier, and A. Mueller et al., EnMAP - A hyperspectral sensor for environmental mapping and analysis, International Geoscience and Remote Sensing Symposium (IGARSS) (2006), pp. 1617-1619.

Kiang et al., 2007 N. Y. Kiang, J. Siefert, Govindjee, and R. E. Blankenship, Spectral signatures of photosynthesis. I. Review of Earth organisms, Astrobiology 7 (2007), pp. 222-251.

Kim, $1973 \rightarrow$ H. H. Kim, New algae mapping techniques by the use of airborne laser fluorosensor, Applied Optics 12 (1973), pp. 1454-1459.

Knipling, $1970 \triangleright$ E. B. Knipling, The physical and physiological basis for the reflectance of visible and near-infrared radiation from vegetation, Remote Sensing of Environment 1 (1970), pp. 155-159.

Kochubey and Kazantsev, $2007 \rightarrow$ S. M. Kochubey and T. A. Kazantsev, Changes in the first derivatives of leaf reflectance spectra of various plants induced by variations of chlorophyll content, Journal of Plant Physiology 164 (2007), pp. 1648-1655.

Kokaly and Clark, 1999 R. F. Kokaly and R. N. Clark, Spectroscopic determination of leaf biochemistry using band-depth analysis of absorption feature and stepwise multiple regression, Remote Sensing of Environment 67 (1999), pp. 267-287

Latimer, $1983-$ P. Latimer, The deconvulation of absorption spectra of green plant materials - Improved corrections for the sieve effect, Photochemistry and Photobiology 38 (1983), pp. 731-734.

le Maire et al., $2004-$ G. le Maire, C. Francois, and E. Dufrene, Towards universal broad leaf chlorophyll indices using PROSPECT simulated database and hyperspectral reflectance measurements, Remote Sensing of Environment 89 (2004), pp. 1-28.

Lichtenthaler, $1987 \rightarrow$ H. K. Lichtenthaler, Chlorophylls and carotenoids: Pigments of photosynthetic biomembranes, Methods in Enzymology 148 (1987), pp. 350-382.

Lichtenthaler, $1988-$ H. K. Lichtenthaler, , Applications of chlorophyll fluorescence. In: H. K. Lichtenthaler, Editor, Photosynthesis Research, Stress Physiol ogy, Hydrobiology, and Remote Sensing, Springer (1988) 384 pp.

Lichtenthaler and Rinderle, $1988 \triangleright$ H. K. Lichtenthaler and U. Rinderle, The role of chlorophyll fluorescence in the detection of stress conditions in plants, CRC Critical Reviews in Analytical Chemistry 19 (Suppl. 1) (1988), pp. S29-S85.

Maccioni et al., 2001 A. Maccioni, G. Agati, and P. Mazzinghi, New vegetation indices for remote measurement of chlorophylls based on leaf directional reflectance spectra, Journal of Photochemistry and Photobiology. B, Biol ogy 61 (2001), pp. 52-61.

Maier, 2000 Maier, S. W. (2000), Modeling the radiative transfer in leaves in the $300 \mathrm{~nm}$ to $2.5 \mu \mathrm{m}$ wavelength region taking into consideration chlorophyll fluorescence - The leaf model SLOPE. PhD Thesis - Technische Universität München (München), 124 pages.

Maier et al., 1999 S. W. Maier, W. Lüdeker, and K. P. Günther, SLOP: A revised version of the stochastic model for leaf optical properties, Remote Sensing of Environment 68 (1999), pp. 273-280.

Malenovský et al., $2006 \triangleright$ Z. Malenovský, C. Ufer, Z. Lhotáková, J. G. P. W. Clevers, M. E. Schaepman, and J. Albrechtová et al., A new hyperspectral index for chlorophyll estimation of a forest canopy: Area under curve normalised to 
maximal band depth between 650-725 nm, EARSeL eProceedings vol. 5 (2006), pp. 161-172.

McClendon and Fukshansky, $1990 \rightarrow$ J. H. McClendon and L. Fukshansky, On the interpretation of absorption spectra of leaves. II. The non-absorbed ray of the sieve effect and the mean optical pathlength in the remainder of the leaf, Photochemistry and Photobiology 51 (1990), pp. 211-216.

Meroni and Colombo, 2006 M. Meroni and R. Colombo, Leaf level detection of solar induced chlorophyll fluorescence by means of a subnanometer resolution spectroradiometer, Remote Sensing of Environment 103 (2006), pp. 438-448.

Merzlyak and Chivkunova, $2000 \rightarrow$ M. N. Merzlyak and O. B. Chivkunova, Light stress induced pigment changes and evidence for anthocyanin photoprotection in apple fruit, Journal of Photochemistry and Photobiology (B) 55 (2000), pp. 154-162.

Middleton et al., 2008 E. M. Middleton, L. A. Corp, and P. K. E. Campbell, Comparison of measurements and FluorMOD simulations for solar-induced chlorophyll fluorescence and reflectance of a corn crop under nitrogen treatments, International Journal of Remote Sensing 29 (2008), pp. 5193-5213.

Miller et al., 1990 J. R. Miller, E. W. Hare, and J. Wu, Quantitative characterization of the vegetation red edge reflectance. 1. An inverted-Gaussian reflectance model, International Journal of Remote Sensing 11 (1990), pp. 1755-1773.

Milton et al., 1983 N. M. Milton, W. Collins, S-H. Chang, and R. G. Schmidt, Remote detection of metal anomalies on Pilot Mountain, Randolph County, North Carolina, Economic Geology 78 (1983), pp. 605-617.

Monteith, 1976 J. L. Monteith, Vegetation and the atmosphere vol. 2, Academic Press, New York (1976).

Nakaji et al., 2005 T. Nakaji, T. Takeda, Y. Fujinuma, and H. Oguma, Effect of autumn senescence on the relationship between the PRI and LUE of young Japanese larch trees, Phyton-Annales Rei Botanicae 45 (2005), pp. 535-542.

Neill and Gould, 1999 S. Neill and K. S. Gould, Optical properties of leaves in relation to anthocyanin concentration and distribution, Canadian Journal of Botany 77 (1999), pp. 1777-1782.

Nelson and Yocum, 2006 N. Nelson and C. F. Yocum, Structure of function of photosystems I and II, Annual Review of Plant Biology 57 (2006), pp. 521-565.

Nichol et al., $2000 \triangleright$ C. J. Nichol, K. F. Huemmrich, T. A. Black, P. G. Jarvis, C. L. Walthall, and J. Grace et al., Remote sensing of photosynthetic-light-use efficiency of boreal forest, Agricultural and Forest Meteorology 101 (2000), pp. 131-142.

Noomen et al., 2006 M. F. Noomen, A. K. Skidmore, F. D. van der Meer, and H. H. T. Prins, Continuum removed band depth analysis for detecting the effects of natural gas, methane and ethane on maize reflectance, Remote Sensing of Environment 105 (2006), pp. 262-270.

Olson and Blankenship, 2004 J. M. Olson and R. E. Blankenship, Thinking about the evolution of photosynthesis, Photosynthetic Research 80 (2004), pp. 373-386.

Peñuelas et al., 1995a $>$ J. Peñuelas, F. Baret, and I. Filella, Semi-empirical indices to assess carotenoids/chlorophyll a ratio from leaf spectral reflectance, Photosynthetica 31 (1995), pp. 221-230.

Peñuelas et al., 1997 J. Peñuelas, J. Llusia, J. Piñol, and I. Filella, Photochemical reflectance index and leaf photosynthetic radiation-use-efficiency assessment in Mediterranean trees, International Journal of Remote Sensing 18 (1997), pp. 2863-2868.

Pinzón et al., 1998 J. E. Pinzón, S. L. Ustin, C. M. Castaneda, and M. O. Smith, Investigation of leaf biochemistry by hierarchical foreground/background analysis, IEEE Transactions on Geoscience and Remote Sensing 36 (1998), pp. 1913-1927.

Porra, 2002 R. J. Porra, The chequered history of the development and use of simultaneous equations for the accurate determination of chlorophylls a and b, Photosynthesis Research 73 (2002), pp. 149-156.

Ramsey and Rangoonwala, $1995 \rightarrow$ E. Ramsey and A. Rangoonwala, Leaf optical property changes associated with the occurrence of Spartina alterniflora dieback in coastal Louisiana related to remote sensing mapping, Photogrammetric Engineering and Remote Sensing 71 (1995), pp. 299-311.

Richards et al., 2003 J. T. Richards, A. C. Schuerger, G. Capelle, and J. A. Guikema, Laser-induced fluorescence spectroscopy of dark-and light-adapted bean (Phaseolus vulgaris L. ) and wheat (Triticum aestivum L. ) plants grown under three irradiance levels and subjected to fluctuating lighting conditions, Remote Sensing of Environment 84 (2003), pp. 323-341.

Richardson et al., 2002 A. D. Richardson, S. P. Duigan, and G. P. Berlyn, An evaluation of noninvasive methods to estimate foliar chlorophyll content, New Phytologist 153 (2002), pp. 185-194.

Richter and Fukshansky, 1996 T. Richter and L. Fukshansky, Optics of a bifacial leaf: 1. A novel combined procedure for deriving the optical parameters, Photochemistry and Photobiology 63 (1996), pp. 507-516.

Roberts et al., 2004 D. A. Roberts, S. L. Ustin, S. Ogunjemiyo, J. Greenberg, S. Z. Dobrowski, and J. Chen et al., Spectral and structural measures of northwest forest vegetation at leaf to landscape scale, Ecosystems 7 (2004), pp. 545-562.

Rock et al., 1988 B. N. Rock, T. Hoshizaki, and J. R. Miller, Comparison of in situ and airborne spectral measurements of the blue shift associated with forest decline, Remote Sensing of Environment 24 (1988), pp. 109-127.

Rühle and Wild, 1979 W. Rühle and A. Wild, The intensification of absorbances in leaves by light-dispersion, Planta 146 (1979), pp. 551-557.

Schaberg et al., 2008 P. G. Schaberg, P. F. Murakami, M. R. Turner, H. K. Heitz, and G. J. Hawley, Association of red coloration with senescence of sugar maple leaves in autumn, Trees- Structure and Function 22 (2008), pp. 573-578.

Seager et al., $2005 \triangleright$ S. Seager, E. L. Turner, J. Schafer, and E. B. Ford, Vege- tation's red edge: A possible spectroscopic biosignature of extraterrestrial plants, Astrobiology 5 (2005), pp. 372-390.

Sellers, 1985 P. J. Sellers, Canopy reflectance, photosynthesis and transpiration, International Journal of Remote Sensing 6 (1985), pp. 1335-1372.

Sellers, $1987 \longrightarrow$ P. J. Sellers, Canopy reflectance, photosynthesis, and transpiration. 2. The role of biophysics in the linearity of their interdependence, $R e-$ mote Sensing of Environment 21 (1987), pp. 143-183.

Sims and Gamon, 2002 D. A. Sims and J. A. Gamon, Relationships between leaf pigment content and spectral reflectance across a wide range of species, leaf structures, and developmental stages, Remote Sensing of Environment 81 (2002), pp. 337-354.

Sims et al., 2006 D. A. Sims, H. Luo, S. Hastings, W. C. Oechel, A. F. Rahman and J. A. Gamon, Parallel adjustments in vegetation greenness and ecosystem $\mathrm{CO} 2$ exchange in response to drought in a Southern California chaparral ecosystem, Remote Sensing of Environment 103 (2006), pp. 289-303.

Stylinski et al., $2001 \rightarrow$ C. D. Stylinski, J. A. Gamon, and W. C. Oechel, Seasonal patterns of reflectance indices, carotenoid pigments and photosynthesis of evergreen chaparral species, Oecologia 131 (2001), pp. 366-374.

Ustin and Curtiss, $1990 \triangleright$ S. L. Ustin and B. Curtiss, Spectral characteristics of ozone treated conifer species, Environmental and Experimental Botany 30 (1990), pp. 293-308.

Ustin et al., 2004 S. L. Ustin, S. Jacquemoud, P. Zarco-Tejada, and G. Asner, "Remote sensing of environmental processes: State of the science and new directions," in Manual of Remote Sensing vol. 4. Remote Sensing for Natural Resource Management and Environmental Monitoring. S. L. Ustin, vol. Ed. ASPRS. New York: John Wiley and Sons, 2004; pp. 679-730.

Ustin et al., 1993 S. L. Ustin, E. W. Sanderson, Y. Grossman, Q. J. Hart, and R. S. Haxo, Relationships between pigment composition variation and reflectance for plant species from a coastal savannah in California. In: Robert O. Green, Editor, Fourth Annual JPL Airborne Geoscience Workshop, NASA, Jet Propulsion Laboratory, Washington, D. C. (1993), pp. 181-184 Oct. 25-27, 1993 JPL 93-26.

Vane et al., 1993 G. Vane, R. O. Green, T. G. Chrien, H. T. Enmark, E. G. Hansen, and W. M. Porter, The airborne visible/infrared imaging spectrometer (AVIRIS), Remote Sensing of Environment 44 (1993), pp. 127-143.

Vogelmann et al., 1993 J. E. Vogelmann, B. N. Rock, and D. M. Moss, Red edge spectral measurements from sugar maple leaves, International Journal of Remote Sensing 14 (1993), pp. 1563-1575.

Wessman, 1990 C. A. Wessman, Evaluation of canopy biochemistry. In: R. J. Hobbs and H. A. Mooney, Editors, Remote Sensing of Biosphere Functioning, Springer-Verlag, New York (1990), pp. 135-156.

Wolstencroft and Raven, 2002 R. D. Wolstencroft and J. A. Raven, Photosynthesis: Likelihood of occurrence and possibility of detection on Earth-like planets, Icarus 157 (2002), pp. 535-548.

Wright et al., $2004 \rightarrow$ I. J. Wright, P. B. Reich, M. Westoby, D. D. Ackerly, Z. Baruch, and F. Bongers et al., The worldwide leaf economics spectrum, Nature 428 (2004), pp. 821-827.

Yamada and Fujimura, 1991 N. Yamada and S. Fujimura, Nondestructive measurement of chlorophyll pigment content in plant leaves from threecolor reflectance and transmittance, Applied Optics 30 (1991), pp. 3964-3973.

Yoder and Pettigrew-Crosby, $1995 \rightarrow$ B. J. Yoder and R. E. Pettigrew-Crosby, Predicting nitrogen and chlorophyll content and concentrations from reflectance spectra (400-2500 nm) at leaf and canopy scales, Remote Sensing of Environment 53 (1995), pp. 199-211.

Zarco-Tejada and Miller, $1999>$ P. J. Zarco-Tejada and J. R. Miller, Land cover mapping at BOREAS using red edge spectral parameters from CASI imagery, Journal of Geophysical Research 104 (D22) (1999), pp. 27921-27933.

Zarco-Tejada et al., $2001 \longrightarrow$ P. J. Zarco-Tejada, J. R. Miller, T. L. Noland, G. H. Mohammed, and P. H. Sampson, Scaling-up and model inversion methods with narrowband optical indices for chlorophyll content estimation in closed forest canopies with hyperspectral data, IEEE Transactions on Geoscience and Remote Sensing 39 (2001), pp. 1491-1507.

Zarco-Tejada et al., $2006>$ P. J. Zarco-Tejada, J. R. Miller, R. Pedros, W. Verhoef, and M. Berger, FluorMODgui V3. 0: A graphic user interface for the spectral simulation of leaf and canopy chlorophyll fluorescence, Computers and Geosciences 32 (2006), pp. 577-591.

Zarco-Tejada et al., $2003 \rightarrow$ P. J. Zarco-Tejada, J. C. Pushnik, S. Dobrowski, and S. L. Ustin, Steady-state chlorophyll fluorescence detection from canopy derivative reflectance and double-peak effects, Remote Sensing of Environmen 84 (2003), pp. 283-294

Zarco-Tejada et al., 2005a P. J. Zarco-Tejada, S. L. Ustin, and M. L. Whiting, Temporal and spatial relationships between within-field yield variability in cotton and high-spatial hyperspectral remote sensing imagery, Agronomy Journal 97 (2005), pp. 641-653.

Zarco-Tejada et al., 2005b $>$ P. J. Zarco-Tejada, A. Berjón, R. López-Lozano, J. R Miller, P. Martín, V. Cachorro, et al., Assessing vineyard condition with hy perspectral indices: Leaf and canopy reflectance simulation in a row-structured discontinuous canopy, Remote Sensing of Environment 99 (2005), pp. 271-287.

Zur et al., 2000 Y. Zur, A. A. Gitelson, O. B. Chivkunova, and M. N. Merzlyak, The spectral contribution of carotenoids to light absorption and reflectance in green leaves, Proceedings of the Second International on Geospatial Information in Agriculture and Forestry Conference, Lake Buena Vista, Florida, 10-12 January, 2000, vol. 2 (2000), pp. II-17-II-23. 